\title{
Edukasi Pengelolaan Lingkungan Permukiman pada Daerah Terdampak Abrasi Desa Bajoe
}

\author{
La Hamimu $^{1 *}$, Bahdad ${ }^{1}$, Laode Ikhsan Juarzan ${ }^{1}$, Fitriani $^{2}$, La Ode Andimbara ${ }^{2}$, Alfirman ${ }^{2}$ \\ ${ }^{1}$ Jurusan Geofisika, ${ }^{2}$ Jurusan Geografi \\ Fakultas Ilmu dan Teknologi Kebumian Universitas Halu Oleo \\ Kampus Hijau Bumi Tridharma Anduonohu Kambu Kota Kendari 93232 \\ Sulawesi Tenggara \\ *E-mail : fitrianihuni@uho.ac.id
}

DOI: https://doi.org/10.21107/pangabdhi.v7i2.11961

Naskah diterima 20 Agustus 2021, Revisi 20 September 2021, Terbit 29 Oktober 2021

\begin{abstract}
Abstrak
Bajoe Village is one of the coastal areas in Province of Southeast Sulawesi has experienced abrasion within a period of 10 years. So it is necessary to provide education on the management of the residential environment that will be affected by abrasion. The method used is the analysis of satellite images using google aerth and SAS Planet, and the lecture method. The result of this activity is that in Tiga Hamlet, it was detected that coastal abrasion had occurred, so that mangrove planting was carried out in Tiga Hamlet. Education is carried out for students so that they can clearly see the change in the environment due to abrasion in Bajoe Village.Then have a discussion with the village head as a stakeholder about the results obtained so that it expected to provide consideration in making decisions on the development of Bajoe Village.
\end{abstract}

Key Words : abrasion, sattlement, management

\section{PENDAHULUAN}

Kabupaten Konawe merupakan salah satu kabupaten yang terdapat di Propinsi Sulawesi Tenggara yang mengalami gejala perubuhan terhadap garis pantai yang terdapat di kawasan pesisir Kecamatan Soropia. Pada tahun 2016 Halim et al., (2016) melakukan penelitian yang menunjukkan bahwa adanya perubahan terhadap akar pohon kelapa yang telah bersentuhan secara langsung terhadap garis pantai dan terkikis oleh gelombang sehingga menyebabkan abrasi.

Proses abrasi yang terjadi di Desa Bajoe Kecamatan Soropia diperlihatkan dengan berkurangnya mangrove, kawasan permukiman yang semakin banyak disekitar pantai, adanya pembangunan dinding pantai yang dapat mempengaruhi pola pergerakan arus yang dapat berfungsi sebagai penyebab penyebaran sedimen di sekitar pantai. Hal ini sejalan dengan pendapat Shuhendry (2004) yang menyatakan penyebab terjadinya perubahan garis pantai akibat adanya kegiatan manusia, seperti alih fungsi lahan pelindung pantai dan pembangunan kawasan pesisir yang tidak sesuai dengan ketentuan yang berlaku. Hal ini menyebabkan ketidak seimbangan transpor sedimen di sepanjang pantai.
Abrasi yang terjadi berdampak bagi permukiman warga yang berbada di pinggir pantai. Dampak abrasi yang mengakibatkan banyak permasalahan seperti hilangnya lahan pemukiman, lahan pertambakan dan mata pencaharian yang berdampak langsung pada penurunan kualitas hidup masyarakat. Kondisi lingkungan dan sumberdaya alam pesisir yang rentan tersebut berdampak pada aspek sosial ekonomi dan sosial budaya penduduk (Hadi 2005 dalam Damayanti, 2013). Abrasi juga dapat membuat kehidupan nelayan dapat semakin terpuruk karena akan berpengaruh pada hasil tangkapan nelayan, menyebabkan lokasi penangkapan nelayan lebih jauh sehingga biaya operasional yang dikeluarkan lebih besar dan akibatnya terjadi penurunan keuntungan.

Kecamatan Soropia merupakan salah satu daerah yang memiliki kawasan pesisir dan secara langsung mendapatkan pengaruh hempasan gelombang laut dari Laut Banda (Halim et al., 2016). Pengaruh gelombang ini menyebabkan terjadinya perubahan garis pantai dan menyebabkan adanya akresi dan abrasi. Berdasarkan penelitian Halim et al., (2016) berdasarkan pembagian wilayahnya, secara umum garis pantai di Kecamatan Soropia bagian 
Tenggara (Desa Sorue Jaya, Desa Tapulaga, Desa Leppe, Desa Bajo Indah, Desa Mekar, Desa Bajoe dan Desa Bokori) menunjukan adanya proses akresi pada tahun 1990 - 2002. Perubahan garis pantai yang berupa abrasi mulai terjadi pada Desa Sorue Jaya, Desa Tapulaga, Desa Bajoe, dan Desa Bokori pada Tahun 2002 - 2014.

\section{METODE}

\section{Lokasi dan Partisipasi Kegiatan}

Kegiatan Kuliah Kerja Nyata (KKN) telah dilakukan di Desa Bajoe Kecamatan Soropia (Gambar 1) dan dilaksanakan pada bulan Agustus - September 2021 dengan sasaran pada lokasi yang dapat ditanamkan mangrove. Partisipan dari edukasi ini adalah para siswa sekolah dasar, sekolah menengah pertama di Desa Bajoe, dan berdiskusi dengan Kepala Desa Bajoe sebagai stakeholder.

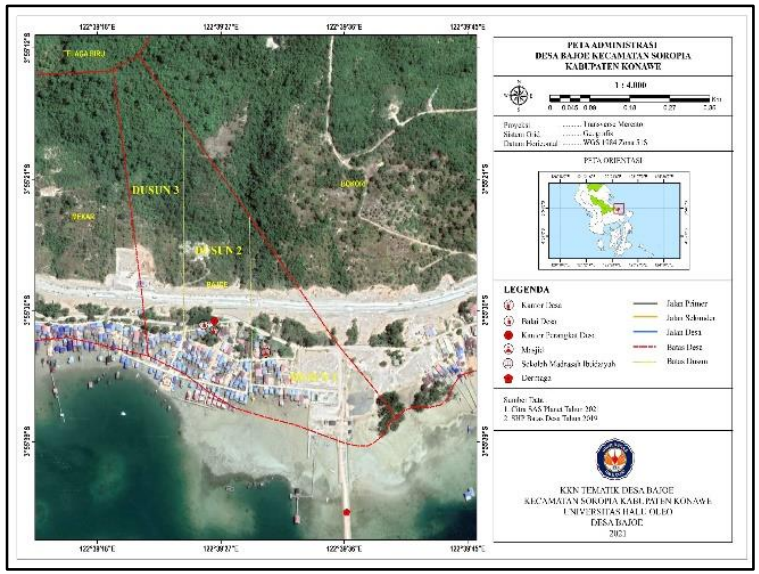

Gambar 1. Lokasi Pengabdian Masyarakat Desa

\section{Pelaksanaan Kegiatan} Bajoe

Metode pelaksanaan kegiatan pengabdian masyarakat ini difokuskan pada upaya pendeteksian abrasi dengan menganalisis perubahan garis pantai yang terjadi di Desa Bajoe melalui aplikasi sistem informasi geografis. Metode ceramah salah satu metode yang digunakan dalam pengabdian ini untuk mengedukasi masyarakat tentang abrasi dan pentingnya mangrove sebagai salah satu upaya dalam meminimalisir terjadinya dampak abrasi. Bagian ini mendeskripsikan lokasi dan khalayak sasaran, bahan dan alat, metode pelaksanaan, metode pengumpulan data, pengolahan dan analisis data dan metode analisis data.

\section{HASIL PEMBAHASAN \\ Pengkajian Resiko Abrasi di Desa Bajoe}

Pengkajian resiko abrasi di Desa Bajoe dilakukan dengan mengetahui perubahan garis pantai pada tahun 2010, 2015 dan 2020. Hal ini dilakukan untuk keperluan perencanaan dan pengelolaan terhadap kawasan pantai di Desa Bajoe. Teknologi yang sering digunakan dalam pemantauan perubahan garis pantai adalah dengan menggunakan teknologi pengindaraan jauh melalui perekaman citra satelit. Memetakan perubahan garis pantai di Desa Bajoe Tahun 20102020 dengan menggunakan perbandingan citra satelit. Adapun prosedur kerja pengolahan citra Desa Bajoe dengan mendowload citra dari Google Earth dan citra SAS Planet. Berdasarkan hasil analisis citra satelit Desa Bajoe pada tahun 2010 dan 2015, Desa Bajoe mengalami penambahan dataran secara umum sehingga mempengaruhi luas daerah administrasi. Pada Gambar 2 terlihat bahwa perubahan garis pantai yang cukup signifikan karena adanya penimbunan pada Dusun I, Dusun II, dan Dusun III.

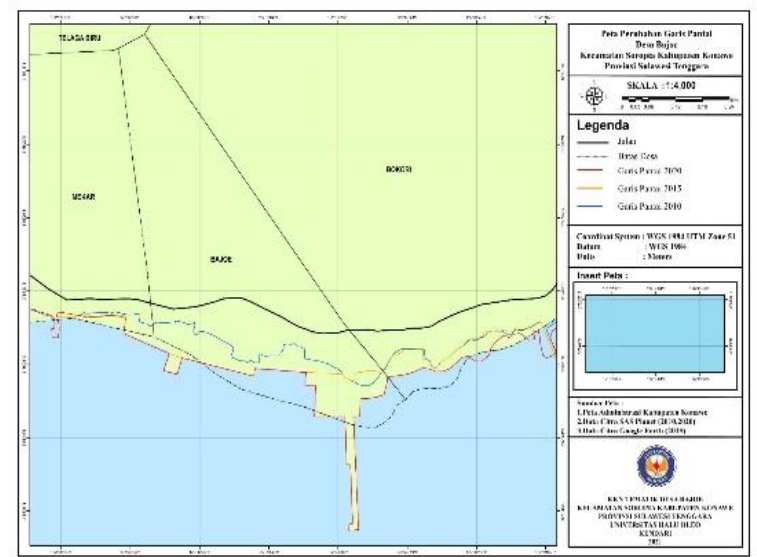

Gambar 2. Peta Perubahan Garis Pantai Desa Bajoe Tahun 2010, 2015 dan 2020

Desa Bajoe mengalami penambahan daratan secara umum pada 10 tahun terakhir yang disebabkan oleh penambahan luasan kawasan permukiman. Pada tahun 2010 luas kawasan permukiman yaitu seluas 3,28 $\mathrm{Ha}$, pada tahun 2015 seluas 3,31 Ha dan pada tahun 2020 seluas 4,39 Ha. Hal ini diikuti dengan penambahan luas dataran. Luas daratan Desa Bajoe pada tahun 2010 yaitu 16,99 Ha, pada tahun 2015 seluas $17,18 \mathrm{Ha}$ dan tahun 2020 seluas 20,62 Ha. Pada tahun 2010 Desa Bajoe pada Dusun Tiga masih terlihat pohon mangove yang melindungi sebagaian daratan sebagai pemecah ombak agar daratan terlindungi. Namun pada tahun 2015 dapat terlihat bahwa tanaman mangrove mengalami penurunan 
sehingga menjadi salah satu penyebab terjadinya abrasi yang terjadi di Dusun III.

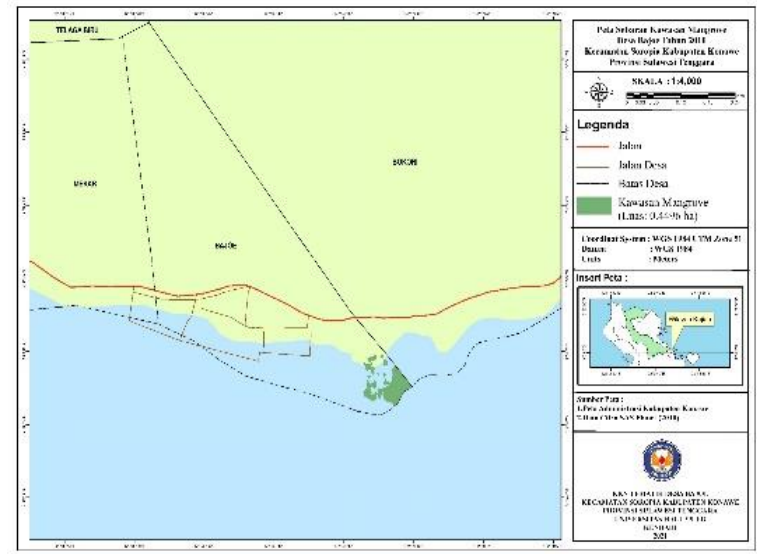

Gambar 4. Peta Keberadaan Mangrove di Desa Bajoe Tahun 2010

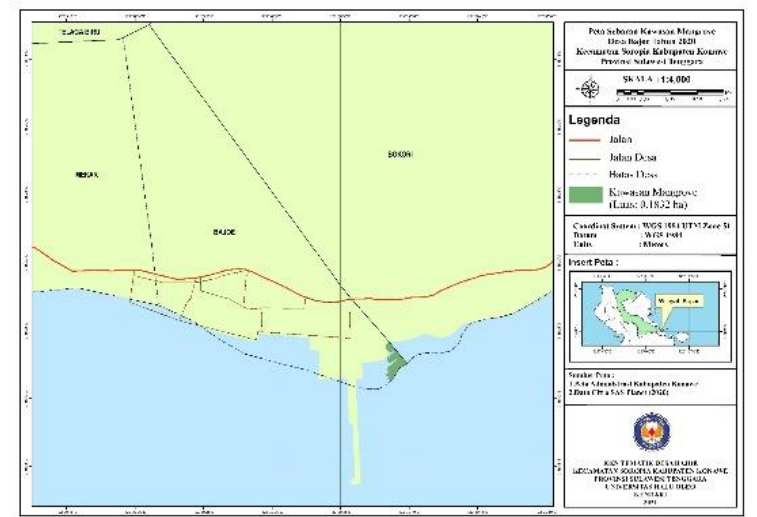

Gambar 5. Peta Keberadaan Mangrove di Desa Bajoe Tahun 2020

Perubahan ini tidak hanya disebabkan oleh proses abrasi, namun didukung dengan aktivitas manusia yang menyebabkan terjadinya pengurangan daratan, yaitu adanya penebangan pohon mangrove. Penebangan ini dapat terlihat pada batang pohon mangrove yang masih tersisa dan meninggalkan bekas pembakaran. Hal ini menunjukkan bahwa belum adanya kesadaran secara utuh pentingnya keberadaan mangrove di wilayah pesisir yang berpotensi untuk mengalami abrasi pantai. Mangrove merupakan salah satu alternatif yang dapat digunakan untuk meminimalisir dampak abrasi. Syah (2020), menyatakan bahwa secara fisik mangrove berperan sebagai penahan ombak, penahan angin, pengendali angin, perangkap sedimen dan penahan intrusi air asin, sedangkan pernanannya di lingkungan biota yaitu sebagai tempat persembunyian, tempat perkembangbiakan berbagai macam biota air. Arief (2007) menyatakan mangrove memberikan perlindungan kepada berbagai organisme lain baik hewan darat maupun hewan air untuk bermukim dan berkembang biak. Pembangunan dermaga sebagai tempat penyebrangan harus memperhatikan ketahanan terhadap ombak yang dapat merusak tanggul (Gambar 6). Lokasi pembangunan dermaga merupakan lokasi tempat terjadinya abrasi, sehingga perlu adanya penjagaan terhadap tanggul yang telah dibangun. Penjagaan ini dengan menghadirkan pemecah ombak, salah satu yang menjadi alternatif yaitu penanaman mangorove. Hal ini dilakukan untuk menjaga keseimbangan lingkungan dan mengembalikan kembali habitat mangrove yang telah berkurang dalam kurun waktu 10 tahun.

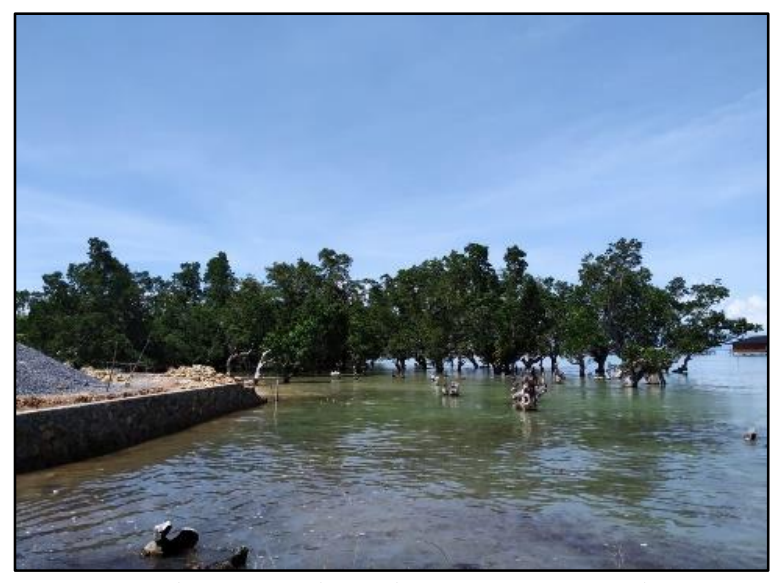

Gambar 6. Keberadaan Mangrove dan Pembuatan Tanggul di Desa Bajoe

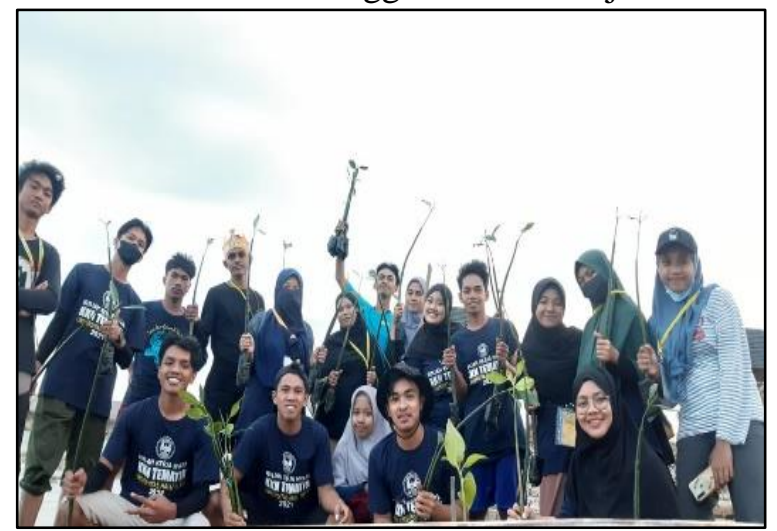

Gambar 7. Penanaman Bibit Mangrove

Pada program KKN tematik melakukan program penanaman mangrove (Gambar 7) sebagai upaya dalam menjaga lingkungan. Penanaman mangrove dilakukan di Dusun Tiga Desa Bajoe, agar lahan mangrove yang telah berkurang dapat bertambah kembali dan diharapkan dapat memberikan gambaran kepada masyarakat bahwa pentingnya menjaga keberadaan mangrove sebagai keseimbangan lingkungan, dan untuk meminimalisir terhadap dampak abrasi yang terjadi di Desa Bajoe. 
Spesies yang digunakan dalam program ini yaitu Rhizophora mucronata. Mangrove ini mempunyai nama daerah diantaranya bakau, bakau gundul, bakau genjah dan bangko. Spesies ini termasuk ke dalam family Rhizophoraceae dan banyak ditemukan pada daerah berpasir serta daerah pasang surut air laut. Penanaman bibit mangrove yang dilaksanakan di Desa Bajoe mengalami kendala, karena pasang surut yang tidak menentu, dan ombak yang dapat menyebabkan terganggunya tumbuh kembang bibit mangrove. Pada keadaan ini maka dilakukan upaya yaitu dengan mengisi karung dengan pasir kemudian diletakkan di depan lokasi penanaman bibit mangrove sebagai upaya penghalang bibit mangrove terkena hempasan ombak secara langsung. Idrus et al., (2018) menyatakan tidak adanya barisan mangrove, sama dengan tidak adanya 'penjaga pantai'. Mangrove seakan menjadi penjaga daratan dari bahaya-bahaya yang datang dari lautan.

\section{Edukasi Pengelolaan lingkungan di Sekolah}

Sosialisasi kepada masyarakat juga dilakukan sebagai upaya edukasi dan penguatan program yang telah dilakukan di Desa Bajoe. Adapun sosialisasi dilaksanakan di sekolah-sekolah, karena sekolah tempat pelaksanaan proses belajar mengajar. Sosialisasi ini dilaksanakan di Madrasah Bahrul Mubarak Toronipa yang dihadiri oleh siswa-siswa kelas 5 dan kelas 6.

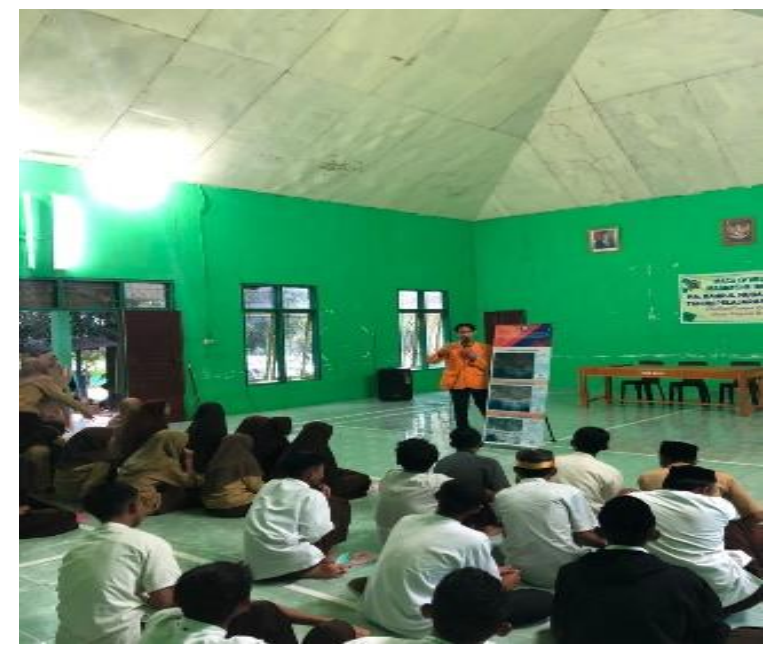

Gambar 8. Sosialisasi Dampak Abrasi

Pihak sekolah memberikan apresiasi terhadap kegiatan yang dilakukan, karena dapat memberikan gambaran mengenai kejadian alam yang terdapat dilingkungan sekitar khususnya di Desa Bajoe. Sosialisasi ini juga didukung dengan penggunaan LCD dan menampilkan peta hasil dari pengolahan citra satelit sehingga para siswa dapat melihat secara jelas perubahan lingkungan karena adanya abrasi di Desa Bajoe

\section{KESIMPULAN}

Kegiatan pengabdian pada masyarakat ini telah berlangsung sehingga dapat diambil kesimpulan bahwa: (1) proses pembuatan peta perubahan garis pantai sehingga dapat terlihat tempat terjadi abrasi, sehingga lokasi penanaman mangrove dapat ditentukan; (2) tim pengabdian masyarakat memberikan edukasi peran dan fungsi mangrove untuk meminimalisir dampak abrasi di Desa Bajoe; (3) pemberian peta perubahan Desa Bajoe selama 10 tahun terakhir dapat dilaksanakan dan (4) peserta yang mengikuti edukasi telah mendapat gambaran tentang pentingnya mempertahankan keberadaan mangrove di lingkungan pesisir.

\section{DAFTAR PUSTAKA}

Arief. 2007. Hutan Mangrove, Fungsi dan Manfaatnya. Yogyakarta: Kanisius

Hadi, P.Sudharto. 2005. Dimensi Lingkungan Perencanaan Pembangunan. Gajahmada University Press. Yogyakarta

Halim, Halili, dan La Ode Alirman Afu. 2016. Studi Perubahan Garis Pantai Dengan Pendekatan Penginderaan Jauh Di Wilayah Pesisir Kecamatan Soropia. Sapa Laut, 1 (1) 24-31

Idrus, Agil Al, M. Liwa Ilhamdi, Gito Hadiprayitno, Gde Mertha. 2018. Sosialisasi Peran dan Fungsi Mangrove Pada Masyarakat di Kawasan Lombok Timur. Jurnal Pengabdian Magister Pendidikan IPA, (1)1: 52-59

Syah, Achmad Fachrudin. 2020. Penanaman Mangrove sebagai Upaya Pencegahan Abrasi di Desa Socah Kabupaten Bangkalan. Jurnal Pangabdhi 6(4) : 14-16 